\title{
A critical survey of optimization methods in industrial forest plantations management
}

\author{
Pedro Belavenutti ${ }^{*}$, Carlos Romero, Luis Diaz-Balteiro
}

Technical University of Madrid (Universidad Politécnica de Madrid) - Dept. of Forest and Environmental Engineering and Management, Ciudad Universitaria, $\mathrm{s} / \mathrm{n}-28040$ - Madrid - Spain.

*Corresponding author <inv.floresta|@gmail.com>

Edited by: Rafael Rubilar Pons

Received November 28, 2016

Accepted March 26, 2017

\begin{abstract}
The application of optimization methods to forest management has given rise to a successful line of investigation in recent decades. However, there have been few publications associated with the application of these techniques to the management of industrial forest plantations (those with short or medium rotations, always less than 50 years), which consider the important role played by these forest systems in the supply of diverse goods and services. This study presents an overview of this literature which, by analyzing 67 articles published in journals contained in the ISI Web of Science, highlight, among other aspects, the techniques employed, their evolution, their planning type (strategic, tactical or operational), the functional objectives and constraints considered, or the type of software deployed in these studies. The results show how Model I has been the one most frequently used in these studies, and how the spatial component is increasing in importance. However, classic optimization methods, such as mixed integer programming, have been those most commonly resorted to, although the employment of multi-criteria techniques such as goal programming and analytic hierarchical process have strongly emerged in recent years.
\end{abstract}

Keywords: mathematical programming, forest management, industrial plantations, timber harvest scheduling

\section{Introduction}

In spite of the growing relevance of industrial plantations to the supply of different outputs (Landsberg and Waring, 2014), studies analyzing the optimization tools most often used in the management of these forest systems are scarce. This is a striking situation, given that the management of these intensive plantations requires methods able to provide the manager with solutions to achieve the stated objectives. Thus, in specific forest plantation management books, there are few chapters devoted to these topics (e.g., Evans, 2009; Bauhus et al., 2010), with the exception of Weintraub et al. (2007) and Borges et al. (2014a).

Bearing this in mind, when briefly analyzing the literature on forest management and the application of the main mathematical optimization methods, the use of which differentiates these plantations, we find (as shown in Table 1) that the number of articles on the use of these techniques in forest plantations, published in the ISI Web of Science is, again, somewhat scarce. Thus, by undertaking a search process referring to the technique used (plus "forest management"), and repeating the operation excluding the plantations ("not plantations"), the number of studies which actually relate to plantations can be identified by subtracting the latter from the former. From the data in the table, it can be seen that in no case did the studies published reach $10 \%$, and the average is below $5 \%$.

In short, these results show that, in forestry literature, the application of these techniques has focused on other types of forests. In this study, we aimed to analyze the employment of these techniques in industrial forest
Table 1 - Percentage of papers dealing with optimization techniques in forest management cases and in plantations.

\begin{tabular}{lccc}
\hline & Total & Plantations & $\%$ \\
\hline Linear Programming & 241 & 14 & 6 \\
Multi-Criteria & 187 & 4 & 2 \\
Heuristics & 161 & 5 & 3 \\
Analytic Hierarchical Process (AHP) & 100 & 5 & 5 \\
Goal Programming (GP) & 98 & 8 & 8 \\
Dynamic Programming (DP) & 97 & 8 & 8 \\
Simulated Annealing & 66 & 0 & 0 \\
Integer Linear programming (ILP) & 51 & 2 & 4 \\
Multiobjective Programming (MOP) & 50 & 2 & 4 \\
\hline Total & 1042 & 48 & 5 \\
\hline
\end{tabular}

Source: ISI Web of Science.

plantations, following the definitions provided by Rodriguez et al. (2014), and critically examine a number of the issues currently being presented as the most important ones in the literature. In other words, the purpose of this paper was to not only undertake a survey of the use of a particular optimization method, but to also furnish the debate with arguments in order to help researchers and managers arrive at a more sensible use of these methods in the forest plantation field. Although there are several surveys on the application of these techniques in the broad field of forest management (e.g., Weintraub and Bare, 1996; Diaz-Balteiro and Romero, 2008; Uhde et al., 2015), to our knowledge, there are none specifically focused on this type of forest system. The same can be said in a contrary manner: reviews of forest plantations usually ignore the use of mathematical optimization approaches (Brockerhoff et al., 2008; Paquette and Messier, 2010; Pawson et al., 2013). 


\section{Materials and Methods}

A search has been made centered exclusively on articles appearing in the database ISI Web of Science (WOS) introducing the following search terms: "forest\$plantation* AND harvest\$schedule* OR operational\$research* OR linear\$program* OR integer\$program* OR non\$linear* OR multi\$criteria* OR decision $\$$ system* $*$ OR goal\$program* OR multi\$objective* OR analytic\$process* OR stochastic\$optimization* OR heuristic*". These searches were updated as of July 21, 2016. As a result, 203 articles were obtained and filtered to arrive at a final figure of 67 papers. A complete categorization of these papers according to different classificatory criteria is shown in Appendix 1.

One of the main reasons for filtering the initial set of 203 papers was the consideration of the term 'plantation' in short or medium rotations. Thus, 50 years of age was selected as a top limit for the rotation cut-off point, and we discarded 36 papers in accordance with this criterion. At this age, the appeal of the industry is reduced, and certain authors already talk about "older aged stands" (Pawson et al., 2013). Another reason for the exclusion of certain studies was the consideration of the industrial purpose of the plantations. Only those articles in which it was clear that the plantation was of an industrial nature (trees managed for industrial purposes) were considered. Thus, we deleted 32 papers related to restoration and conservation issues. Furthermore, we have not included papers based on uneven-aged stands (33) nor studies (36) whose objectives were exclusively non-productive objectives related to forest plantations, such as fire control and natural resource conservation. Finally, due to length constraints, we decided not to incorporate an explanation about the main features of the different optimization methods used in the field surveyed. Readers can find a description of these methods in other studies such as Diaz-Balteiro and Romero (2008), Kangas et al. (2015); Yoshimoto et al. (2016); Ezquerro et al. (2016).

\section{Forest planning and industrial plantations}

In this section, the principal results of the bibliographical search made are shown, emphasizing topics which frequently appear when these techniques are employed. A number of these issues have been studied in specific generic papers (e.g., Rönnqvist et al., 2015), but in our study certain concrete aspects of this type of forest system were highlighted. The numerical results of the search have been given in Appendix 1, where the topics follow the same numbering as the following subsections.

\section{General aspects}

As mentioned previously, 67 papers in all corresponding to the period from 1986-2016 were selected. As can be seen in Appendix 1 (3.0), 68 \% corresponded to case studies, the rest being methodology proposals. Al- most all the studies used deterministic techniques and, from a geographical perspective, Brazil was the country most represented providing nearly $38 \%$ of the papers, followed a good distance behind by countries such as Spain, Chile, Colombia, Cuba, Mexico, New Zealand and Venezuela. Moreover, the species most commonly represented were those belonging to the genus Eucalyptus (in $53 \%$ of the papers), followed by those corresponding to the genus Pinus (30\% of the papers). As for expansion over time, there has been a notable increase since 2000 . In fact, the number of publications in this field in the current century represents almost $90 \%$ of the total number of papers published to date, as is shown in Figure 1.

\section{Are classic optimization techniques those that are usually employed the most?}

First, we grouped the main optimization techniques found in the papers reviewed following a scheme similar to that found in Ezquerro et al. (2016). Three sizeable groups of techniques were defined. The first is called Classic Optimization Techniques and includes: Linear Programming (LP), Integer Programming (IP), Mixed-Integer Programming (MIP) and Dynamic Programming (DP). The second group was called Metaheuristics $(\mathrm{MH})$, which includes: Simulated Annealing (SA), Genetic Algorithms (GA) and Tabu Search (TS). Finally, the last group involved Multi-Criteria Decision Making Techniques (MCDM) including the two most widely used methods in the field surveyed: Goal Programming (GP), and Analytic Hierarchical Process (AHP).

The results collected in Appendix 1 (3.1), show, how out of the 3 large groups, classic optimization is the most represented, followed by MCDM techniques, and, finally, the set of $\mathrm{MH}$ methods. With regard to the techniques themselves, and taking those used in at least three studies, the two most recurring ones were MIP and GP. However, what captures the attention is how these techniques were used in a different way according to whether the study reports an actual case study or implies a theoretical reflection. As can be noted in the case of $\mathrm{MH}$, most of the works were theoretical models, whereas in the case of the use of multi-criteria techniques, over $91 \%$ were carried out in case studies.

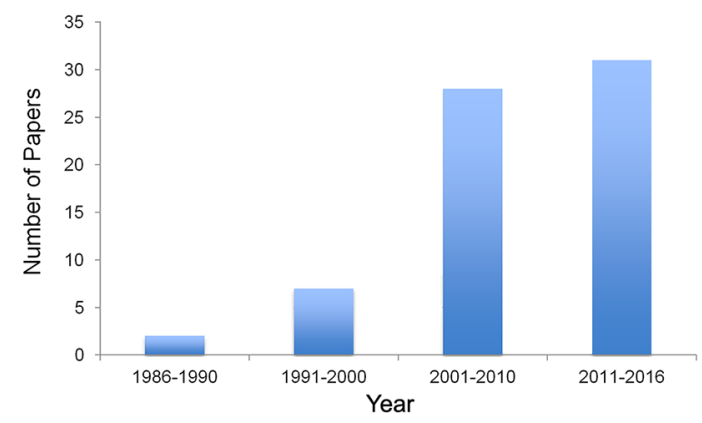

Figure 1 - Temporal evolution of the number of papers. 
Planning levels: strategic, tactical and operational Starting from the basis that, in the literature, different optimization methods have frequently been used to address different forest management problems (Weintraub and Bare, 1996; Kaya et al., 2016; Yoshimoto et al., 2016), the temporal aspect of applying these techniques in industrial forest plantations was analyzed. When considering different planning times, the classic definitions of strategic, tactical and operational levels were taken into account (McDill, 2014; Borges et al., 2014b), bearing in mind that they are usually organized hierarchically (Banhara et al., 2010). In Appendix 1 it is noted that most of the papers analyzed relate to the strategic level, the number of papers on the other two levels being very similar. On the other hand, it is interesting to note that, in seventeen cases, the studies combine more than one level of planning. In this sense, the combination of tactical and operational planning is the most frequent in these cases, as shown in Appendix 1 .

\section{Which strategic forest planning model is most used?}

Once it has been verified that it is at the strategic forest planning stage when these optimization methods are used most, it should be asked which strategic planning model is the one most employed, following the nomenclature of Johnson and Scheurman (1977). The results of our review show that Model I is more commonly applied compared to Model II (Appendix 1, 3.3), although in many cases the authors have not specified the model used. Indeed, only 17 papers specify if Model I or Model II appears. It should be pointed out that although there are signs in other studies that a particular model has been deployed (generally Model I), the criterion of quantifying only those which were explicitly defined by their authors was adopted.

\section{Is the logic still monocriterion or is the tendency for other objectives to be included in these models?}

Figure 2 shows the temporal evolution of the use of optimization methods in these forest systems. It can be seen how they have undergone a notable upsurge since the year 2000, especially with regard to the use of the MH and MCDM methods. In effect, up to that year, there was hardly any representation of these two sizeable groups of techniques. However, in the past few years, their use has increased, especially multi-criteria techniques, whose number from the year 2000 exceeded papers using classic optimization methods.

In Appendix 1 (3.4) it can be seen how the objective function most widely used is the maximization of Net Present Value (NPV). Notwithstanding, in the last few years a significant number of papers including objective functions with a non-productive orientation such as biodiversity conservation and environmental protection have appeared.

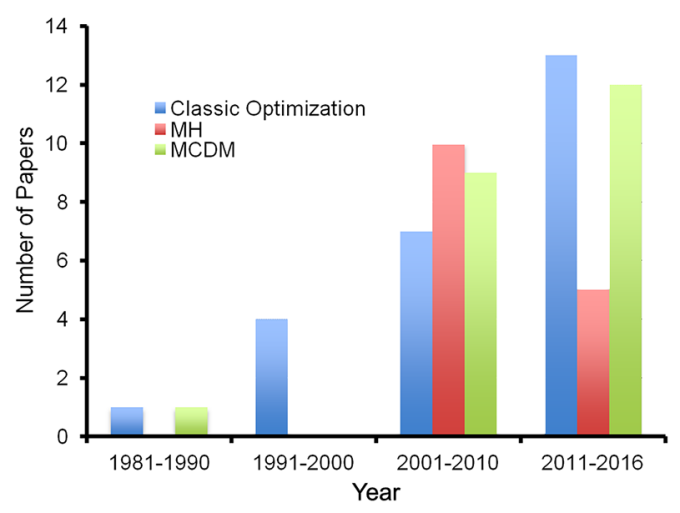

Figure 2 - Temporal evolution of the main optimization technique groups. $\mathrm{MH}=$ Metaheuristics; $\mathrm{MCDM}=$ Multiple Criteria Decision Making.

\section{Other theory developments}

In addition to the techniques described above, on many occasions it is customary to find methodologies combining more than one optimization technique. In such cases, a number of authors call them hybrid methods (Uhde et al., 2015). On the other hand, in recent years, an increase in the application of the Decision Support Systems (DSS) method in forest management (Borges et al., 2014c) has been observed. For this reason, the articles proposing these methods have been quantified. The latest theory development considered has been the use of Group Decision Making (GDM) models in the management of this type of plantation. The results in Appendix 1 (3.5) show how the degree of usage of these methodologies is similar with respect to the others, although those with the greatest presence are the DSS. Although no graph illustrating this fact has been shown, the temporal evolution of the papers employing these techniques does not exactly follow the pattern shown in Figure 2. Thus, DSS were resorted to with greater frequency in the first decade of the $20^{\text {th }}$ century than in the current one. Finally, all the methods considered up to now were of a deterministic nature. No non-deterministic methods (stochastic, Monte Carlo, etc.) have been specified because they were used on very few occasions according to the articles reviewed.

\section{Integration of other non productive objectives}

In section 3.4 of the Appendix it has already been suggested from time to time that the objectives considered in the management of these plantations have not always been of a productive nature. One of the most important objectives, fundamentally due to certain controversies associated with this type of forest system (Calviño-Cancela, 2013), is biodiversity. Another important one is the protection of the ecosystem, related to the quality of the soil, water and landscape (Silva et al., 2010). Along with the eleven studies in which environmental resources appear as objectives, it should be taken into account that, on other occasions, it was decided to introduce them as constraints 
or, indirectly, by what are known as spatial constraints. Although it cannot be said that these constraints are always univocally related to objectives relating to conserving environmental resources, their inclusion in forest management does at least make the achievement of this type of objective easier (Baskent and Keles, 2005). In short, it can be stated that these types of objectives have a growing presence in the management of these plantations. Figure 3 shows this, and it is significant that not until 2007 did the first study considering biodiversity as an objective in industrial forest plantation management appear.

\section{What constraints and decision variables are usually employed the most?}

Appendix 1 (3.7) gives the constraints most commonly incorporated into forest management problems, and the frequency with which they appear in the articles analyzed is quantified. It can be seen that the most frequent constraint is the one associated with the procurement of a certain volume per period, followed by spatial constraints, the achievement of a homogeneous production throughout a specific period of time, and those associated with specific logistic problems. Of all of these, the spatial types stand out, since the results show that they have been used many times in applying strategic planning Model I with the help of binary variables. In many studies, classic optimization methods were used requiring an enormous computational resolution effort (i.e., Augustynczik et al., 2016; Silva et al., 2016). Finally, the type of decision variables used in these models has been calculated. Although cutting area variables remain prevalent, other variables associated with other kinds of problems (logistics, environmental) are significant.

\section{Plantations and sustainability}

For some years, several authors (e.g., Diaz-Balteiro, 2007; Fernandes, 2008; Gerber, 2011; Calviño-Cancela et al., 2012; Andersson et al., 2016) have been proposing to introduce the issue of sustainability into the management of forest plantations, with the purpose of balancing productive and non-productive (e.g., biodiversity conservation) orientations (Calviño-Cancela, 2013).

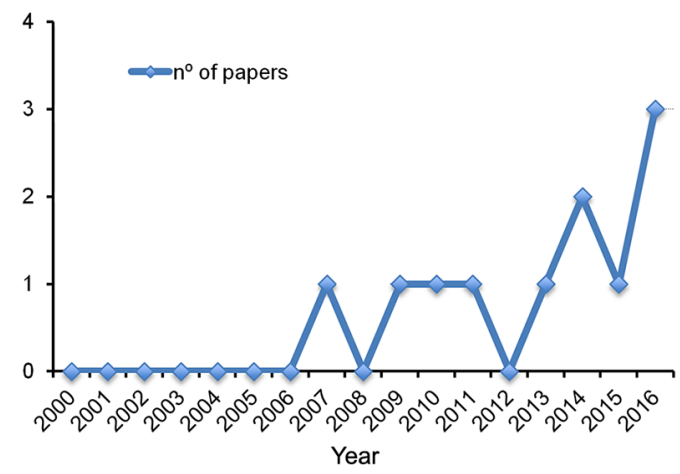

Figure 3 - Temporal evolution of the number of papers which consider biodiversity as an objective.
Given that there is considerable consensus on the idea of tackling sustainability problems by means of a set of criteria and indicators (Wolfslehner and Vacik, 2008), in principle, we find ourselves facing discrete type problems; that is, if we are faced with a finite set of plantations, we must choose the most sustainable one. Indeed, if we accept this type of scenario, it would seem that the MCDM techniques are the most adequate ones because they permit the integration of criteria and indicators of different natures in a very straightforward way (DiazBalteiro et al., 2017). As can be seen in Appendix 1, GP is the MCDM most commonly used technique for the purpose of aggregating criteria and indicators in order to obtain the most sustainable plantation (Diaz-Balteiro et al., 2016a, b), or the most sustainable alternative management for a plantation (Giménez et al., 2013). However, in other instances, and for the same basic purpose, other multi-criteria techniques have been employed.

\section{Results and Discussion}

The survey made on optimization methods for the management of industrial forest plantations has shown that it is a topical and timely subject reaching a very notable publication level in recent years. These types of forest system are of increasing economic importance (Rodriguez et al., 2014), especially in certain countries. However, a direct relationship between countries which produce the most industrial roundwood (following Payn et al., 2015) and the number of papers included in this study should not be expected. In fact, there are few studies emanating from countries such as China, the USA or India. One exception to this is Brazil, the country considered to be the most suitable for making this type of investment in the period from 2005-2011 (Cubbage et al., 2014). However, this result was to be expected, given its immense forest area covered with industrial forest plantations (Rodriguez et al., 2014).

Beginning with the basis that this survey has not aimed to answer the question as to which would be the best technique to apply to the management of these plantations, the results obtained differ from those of Ezquerro et al. (2016), who analyzed 179 papers in a study on their use in problems related to biodiversity conservation. Thus, the classic optimization group is the one least used, and as for those most employed, the favorite is SA, followed by integer linear programming (ILP). Yoshimoto et al. (2016) analyzed forest management optimization methods differentiating stand, forest and landscape levels using a database of 85 papers. In the results at the stand level, MH methods predominated, whereas at the forest level MIP and LP were the most prominent. Those two techniques, in inverse order, were also those most used at the landscape level.

The results of the use of these techniques at the different planning levels habitually considered in forest management show a predominance of strategic planning, although there are numerous examples of tactical and 
operational planning. Despite expectations, considering the problem being dealt with, that there should be many studies devoted to operational planning, this is not commonplace when objectives not having a production orientation such as biodiversity are integrated (Ezquerro et al., 2016). On the other hand, and although integration between the diverse levels is not always easy (Rönnqvist et al., 2015) or univocal (Kangas et al., 2014; McDill, 2014), a high percentage of studies combining more than one management level has been found, specifically, those unifying strategic planning with operational aspects, which seems to provide a balance between economic and environmental benefits (Augustynczik et al., 2016). With regard to the strategic planning models, the reasons for justifying the selection of one or the other are not clear, although, recently, this aspect has triggered an interesting debate in the literature. Thus, McDill et al. (2016) maintain that Model II outperforms Model I the more the periods in the action horizon and the more the silvicultural operations are employed. However, Martin et al. (2017) suggest that Model I outperforms Model II in spatial models. Both conclusions could justify Model I as being the most commonly selected in industrial plantations. In fact, from 2010 onwards, no studies deploying Model II in this type of forest system were found. Additionally, in recent years a percentual increase in studies using MCDM techniques has been observed. This tendency has been seen in other studies reviewed on the employment of MCDM techniques in diverse spheres (Diaz-Balteiro and Romero, 2008; Diaz-Balteiro et al., 2017). However, unlike the work of Diaz-Balteiro and Romero (2008), the number of studies which can be included under the heading "harvest scheduling" or "extended harvest scheduling" is clearly on the rise. There is no doubt that the use of hybrid methodologies enables a resolution of complex problems that would not be easily tackled by any single technique (Hernández et al., 2014). However, the number of papers with this orientation is not very significant. Thus, in Ezquerro et al. (2016) the number of articles in which more than one optimization technique is combined is no more than $35 \%$. This combination of techniques is often clearly present in the context of collective decision-making. Thus, several authors suggest suitable aggregation of the preferences of the different stakeholders in management models for these types of plantations, since these preferences clearly affect the final results obtained (DiazBalteiro et al., 2016a). Finally, it is interesting to note that very few studies in this field incorporate uncertainty or risk elements into the analysis (Yoshimoto et al., 2016). The consideration of biodiversity management as an objective could have obvious implications in aspects like the cutting areas, the forest rotation length employed, silviculture, etc. However, indirectly, these plantations could be of indirect benefit to these non-productive objectives if this does not require altering natural forests (Brockerhoff et al., 2008). Nevertheless, from an operational point of view, the inclusion of this objective usually implies that tactical and operational planning gain in importance, it being necessary to resort to different optimization tools from those of classic linear programming (Ezquerro et al., 2016), including hybrid methods. It is no coincidence that biodiversity has appeared as an objective, as is shown in Figure 2, in a manner parallel to the expansion in the use of $\mathrm{MH}$ and MCDM techniques. As stated by Yoshimoto et al. (2016), the employment of $\mathrm{MH}$ was accentuated when spatial aspects appeared. It should be emphasized that, as shown in Appendix 1, spatial constraints are used reasonably frequently. One of the differentiating aspects in relation to the forest management usually carried out in other forest systems is the comparatively scant presence of constraints generally associated with the idea of a normal forest. Indeed, if it is assumed that this idea can be replicated by obliging simultaneous compliance with regulation conditions, and even-flow and ending forest inventory, it has been verified that, in no case have these constraints been introduced simultaneously. Specifically, it can be seen how the least represented constraint is the one relative to ending forest inventory, and this would seem to be logical since the persistence of these forests is assumed to be ensured. It has been demonstrated that, on occasions, the fulfillment of one of these objectives (even-flow volume) in certain plantations clashes with the achievement of a certain structure in the forest (Bertomeu et al., 2009), in spite of defining diverse GP models. Also, in Piazza and Pagnoncelli (2014), optimal solutions have been found which do not converge into a normal forest structure, whereas Zhai et al. (2014) consider this type of structure to be unrealistic for the plantation case, which is a controversial issue.

\section{Final Remarks}

The use of optimization methods for the management of industrial forest plantations has shown a significant publication level in recent years, especially in countries like Brazil and for species such as Eucalyptus or Pinus. The Operations Research (OR) techniques most frequently employed are linear programming, integer linear programming and an MCDM method (goal programming), but papers which hybridize more than one OR technique are scarce. Finally, the use of nondeterministic scenarios is infrequent.

\section{Acknowledgements}

The work of Carlos Romero and Luis Diaz-Balteiro was funded by the Ministry of Economy and Competitiveness of Spain under project AGL2015-68657-R. Pedro Belavenutti has received funding from the SuFoRun Project ("Models and decision Support tools for integrated Forest policy development under global change and associated Risk and Uncertainty") have been funded by a Marie Curie International Research Staff Exchange Scheme Fellowship within the H2020 European Union Framework Program (H2020-MSCA-RISE-2015). Thanks are extended to Diana Badder for editing the English. 


\section{References}

Andersson, K.; Lawrence, D.; Zavaleta, J.; Guariguata, M.R. 2016. More trees, more poverty? The socioeconomic effects of tree plantations in Chile, 2001-2011. Environmental Management 57: 123-136.

Augustynczik, A.L.D.; Arce, J.E.; Silva, A.C. 2016. Aggregating forest harvesting activities in forest plantations through integer linear programming and goal programming. Journal of Forest Economics 24: 72-81.

Banhara, J.R.; Rodriguez, L.C.E.; Seixas, F.; Moreira, J.M.M.A.P.; Silva, L.M.S.; Nobre, S.; Cogswell, A. 2010. Optimized harvest scheduling in eucalyptus plantations under operational, spatial and climatic constraints. Scientia Forestalis 38: 85-95.

Baskent, E.Z.; Keles, S. 2005. Spatial forest planning: a review. Ecological Modelling 188: 145-173.

Bauhus, J.; van der Meer, P.J.; Kanninen, M. 2010. Ecosystem Goods and Services from Plantation Forests. Earthscan, London, UK.

Bertomeu, M.; Diaz-Balteiro, L.; Giménez, J.C. 2009. Forest management optimization in Eucalyptus plantations: a goal programming approach. Canadian Journal of Forest Resource 39: 356-366.

Borges, J.G.; Diaz-Balteiro, L.; McDill, M.; Rodriguez, L.C.E. 2014a. The Management of Industrial Forest Plantations. Springer, Dordrecht, Netherlands.

Borges, J.G.; Garcia-Gonzalo, J.; Marques, S.; Valdebenito, V.A.; McDill, M.E.; Falcão, A.O. 2014b. Strategic management scheduling. p. 171-238. In: Borges, J.G.; Diaz-Balteiro, L.; McDill, M.; Rodriguez, L.C.E., eds. The Management of industrial forest plantations. Springer, Dordrecht, Netherlands.

Borges, J.G.; Nordström, E.M.; Garcia-Gonzalo, J.; Hujala, T.; Trasobares, A. 2014c. Computer-Based Tools for Supporting Forest Management: The Experience and the Expertise World-Wide. Dept of Forest Resource Management, Swedish University of Agricultural Sciences, Uppsala, Sweden.

Brockerhoff, E.G.; Jactel, H.; Parrota, J.A.; Quine, C.P.; Sayer, J. 2008. Plantation forests and biodiversity: oxymoron or opportunity? Biodiversity Conservation 17: 925-951.

Calviño-Cancela, M.; Rubido-Bará, M.; van Etten, E.J.B. 2012. Do eucalypt plantations provide habitat for native forest biodiversity? Forest Ecology and Management 270: 153-162.

Calviño-Cancela, M. 2013. Effectiveness of eucalypt plantations as a surrogate habitat for birds. Forest Ecology and Management 310: 692-699.

Cubbage, F.; MacDonagh, P.; Balmelli, G.; Olmos, V.M.; Bussoni, A.; Rubilar, R.; De La Torre, R.; Lord, R.; Huang, J.; Hoeflich, V.A.; Murara, M.; Kanieski, B.; Hall, P.; Yao, R.; Adams, P.; Kotze, H.; Monges, E.; Pérez, C.H.; Wikle, J.; Abt, R.; Gonzalez, R.; Carrero, O. 2014. Global timber investments and trends, 2005-2011. New Zealand Journal of Forestry Science 44: S7.

Diaz-Balteiro, L. 2007. Letter to the Editor. Journal of Forest Economics 13: 291-292.

Diaz-Balteiro, L.; Romero, C. 2008. Making forestry decisions with multiple criteria: a review and an assessment. Forest Ecology and Management 255: 3222-3241.
Diaz-Balteiro, L.; Alfranca, O.; Bertomeu, M.; Ezquerro, M.; Giménez, J.C.; González-Pachón, J.; Romero, C. 2016a. Using quantitative techniques to evaluate and explain the sustainability of forest plantations. Canadian Journal of Forest Research 46: 1157-1166.

Diaz-Balteiro, L.; Alfranca, O.; González-Pachón, J.; Romero, C. 2016b. Ranking of industrial forest plantations in terms of sustainability: a multicriteria approach. Journal of Environmental Management 180: 123-132.

Diaz-Balteiro, L.; González-Pachón, J.; Romero, C. 2017. Measuring system sustainability with multi-criteria methods: a critical review. European Journal of Operational Research 258: 607-616.

Evans, J. 2009. Planted Forests: Uses, Impacts, and Sustainability. CABI, Wallingford, UK.

Ezquerro, M.; Pardos, M.; Diaz-Balteiro, L. 2016. Operational research techniques used for addressing biodiversity objectives into forest management: an overview. Forests 7: 229.

Fernandes, P. 2008. Forest fires in Galicia (Spain): the outcome of unbalanced fire management. Journal of Forest Economics 14: 155-157.

Gerber, G.F. 2011. Conflicts over industrial tree plantations in the South: who, how and why? Global Environmental Change 21: 165-176.

Giménez, J.C.; Bertomeu, M.; Diaz-Balteiro, L.; Romero, C. 2013. Optimal harvest scheduling in Eucalyptus plantations under a sustainability perspective. Forest Ecology and Management 291: 367-376.

Hernández, M.; Gomez, T.; Molina, J.; Leon, M.A.; Caballero, R. 2014. Efficiency in forest management: a multiobjective harvest scheduling model. Journal of Forest Economics 20: 236-251.

Johnson, K.N.; Scheurman, H.L. 1977. Techniques for prescribing optimal timber harvest and investment under different objectives: discussion and synthesis. Forest Science Monograph 18: $1-31$.

Kangas, A.; Kurttila, M.; Hujala, T.; Eyvindson, K.; Kangas, J. 2015. Decision Support for Forest Management. 2ed. Springer, Berlin, Germany.

Kangas, A.; Nurmi, M.; Rasinmäki, R. 2014. From a strategic to a tactical forest management plan using a hierarchic optimization approach. Scandinavian Journal of Forest Resource 29: 154165.

Kaya, A.; Bettinger, P.; Boston, K.; Akbulut, R.; Ucar, Z.; Siry, J.; Merry, K.; Cieszewski, C. 2016. Optimisation in forest management. Currently Forestry Reports 2: 1-17.

Landsberg, J.; Waring, R. 2014. Forests in Our Changing World: New Principles for Conservation and Management. Island Press, Washington, DC, USA.

Martin, A.B.; Gunn, E.A.; Richards, E.W. 2017. Comparing the efficacy of LP Models I and II for spatial strategic forest management. Canadian Journal of Forest Research 47: 1627.

McDill. M. 2014. An overview of forest management planning and information management. p. 27-59. In: Borges, J.G.; Diaz-Balteiro, L.; McDill, M.; Rodriguez, L.C.E., eds. The management of industrial forest plantations. Springer, Dordrecht, Netherlands. 
McDill, M.E.; Tóth, S.; St. John, R.; Braze, J.; Rebain, S.A. 2016. Comparing Model I and Model II formulations of spatially explicit harvest scheduling models with maximum area restrictions. Forest Science 62: 28-37.

Paquette, A.; Messier, C. 2010. The role of plantations in managing the world's forests in the Anthropocene. Frontiers in Ecology and Environment 8: 27-34.

Pawson, S.M.; Brin, A.; Brockerhoff, E.G.; Lamb, D.; Payn, T.W.; Paquette, A.; Parrotta, J.A. 2013. Plantation forests, climate change and biodiversity. Biodiversity Conservation 22: 12031227.

Payn, T.; Carnus, J.M.; Freer-Smith, P.; Kimberley, M.; Kollert, W.; Liu, S.; Orazio, C.; Rodriguez, L.; Silva, L.N.; Wingfield, M.J. 2015. Changes in planted forests and future global implications. Forest Ecology and Management 352: 57-67.

Piazza, A.; Pagnoncelli, B.K. 2014. The optimal harvesting problem under price uncertainty. Annals of Operational Research 217: 425-445.

Rodriguez, L.C.E.; Pasalodos-Tato, M.; Diaz-Balteiro, L.; McTague, J.P. 2014. The importance of industrial forest plantations. p. 3-26. In: Borges, J.G.; Diaz-Balteiro, L.; McDill, M.; Rodriguez, L.C.E., eds. The management of industrial forest plantations. Springer, Dordrecht, Netherlands.

Rönnqvist, M.; D'Amours, S.; Weintraub, A.; Jofre, A.; Gunn, E.; Haight, R.G.; Martell, D.; Murray, A.T.; Romero, C. 2015. Operations research challenges in forestry: 33 open problems. Annals of Operations Research 232: 11-40.

Silva, M.; Weintraub, A.; Romero, C.; Maza, C.D. 2010. Forest harvesting and environmental protection based on the goal programming approach. Forest Science 56: 460-472.

Silva, P.H.B.M.; Arce, J.E.; Loch, G.V.; David, H.C.; Fiorentin, L.D. 2016. Forest harvest scheduling plan integrated to the road network. Cerne 22: 69-76

Uhde, B.; Hahn, W.A.; Griess, V.; Knoke, T. 2015. Hybrid MCDA methods to integrate multiple ecosystem services in forest management planning: a critical review. Environmental Management 56: 373-388.

Weintraub, A.; Bare, B.1996. New issues in forest land management from an operations research perspective. Interfaces 26: 9-25.

Weintraub, A.; Romero, C.; Bjorndal, T.; Epstein, R. 2007. Handbook of Operations Research in Natural Resources. Springer, New York, NY, USA.

Yoshimoto, A.; Asante, P.; Konoshima, M. 2016. Stand-level forest management planning approaches. Current Forestry Reports: 163-176.

Zhai, W.; Zhao, Y.; Lian, X.; Yang, M.; Lu, F. 2014. Management planning of fast-growing plantations based on a bi-level programming model. Forest Policy and Economics 38: 173-177.
Appendix 1 - Main search results.

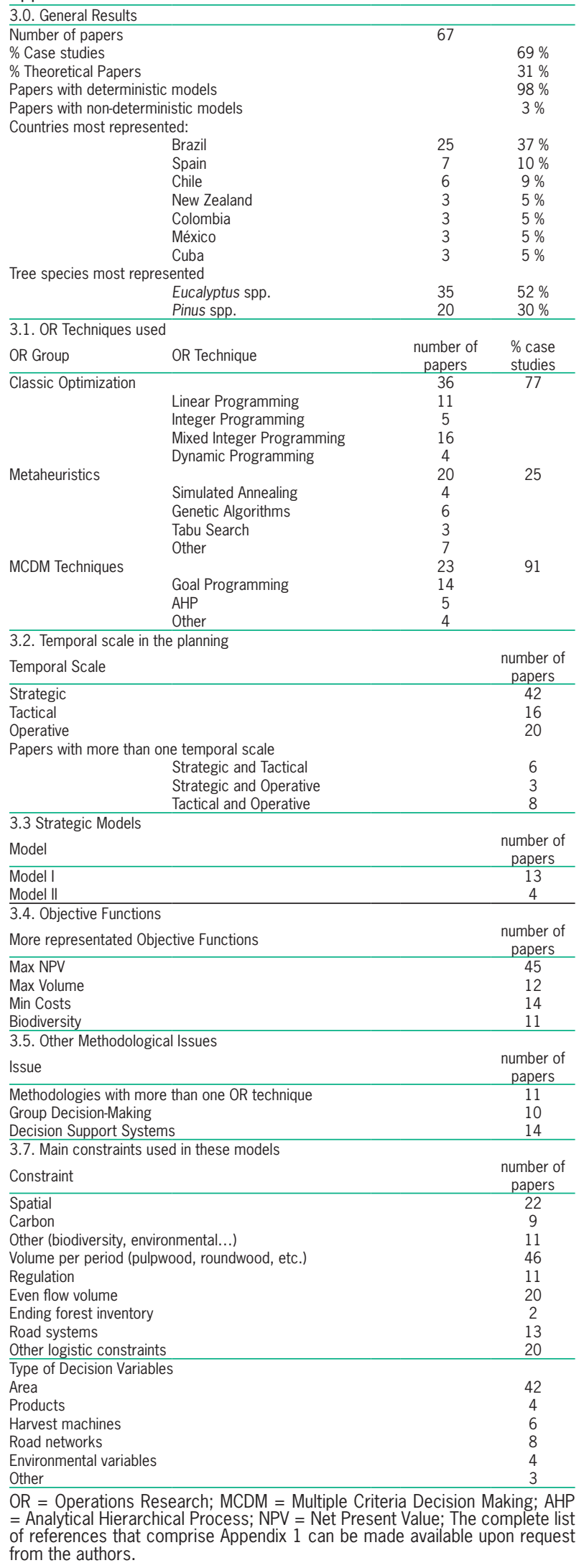

